\title{
LA ESCRITURA EPISTOLAR EN LA ACTUAL ENCRUCIJADA GENÉRICA
}

\author{
Genara Pulido Tirado
}

Universidad de Jaén

La epístola es una manifestación discursiva antiquísima. Aunque hay autores que, como Rico Verdú (1981:133), sitúan su aparición en Roma no podemos ignorar la tradición griega en la que, bien como elemento integrante de una obra literaria o bien de forma independiente, es de justicia citar al menos a Homero (Ilíada, VI), Heródoto y las cartas apócrifas de Aristóteles y Demóstenes. Pero es que además va a ser en la Antigüedad cuando se empiece a teorizar sobre este peculiar tipo de escritura, constituyéndose una Ars Epistolica (Suárez de la Torre, 1988) que aún hoy, dada la confusión teórica que existe en este campo, debemos tener presente. La epístola clásica, entendida tanto en su relación con la literatura como en la Biblia o en sus distintas manifestaciones de tipo administrativo, ha sido objeto de un buen número de estudios críticos. La historia de tan conflictiva forma literaria es amplia y presenta abundante variedad formal, temática y funcional, como ha puesto oportunamente de manifiesto López Estrada (1960), entre otros. 
Sin embargo, la epístola que aquí nos interesa es la moderna, la que surge a partir del siglo XVIII - aunque desde el XV aumenta notablemente su cultivo, ya que ofrece un ámbito de libertad sumamente atractivo tras la desaparición de la sacralizada y estamental Edad Media-, a la par que la burguesía y el concepto de sujeto libre, pues es entonces cuando aparece la carta privada en tanto que manifestación de la privacidad de un sujeto que se la transmite a otro; si bien, también es cierto que tal privacidad se ha visto rota con frecuencia por la publicación de epistolarios que en principio no estaban destinados a un público amplio. Este hecho histórico, el ascenso de la burguesía, va acompañado de otros que influyen de forma decisiva en el aumento de epístolas literarias desde el siglo XVII, como son el desarrollo del sistema postal, el estudio escolar de las epístolas latinas, la moda de la carta familiar en Francia e Inglaterra o la aparición de abundantes manuales de carácter didáctico sobre tal tipo de escritura. Hay que tener en cuenta, en cualquier caso, que en sus inicios muchos de los representantes de la nueva clase emergente sólo tienen acceso a la escritura a través de la carta, la cual se convierte así en un lugar privilegiado y único para manifestar y consolidar la nueva noción de sujeto. El papel que ocupan las mujeres es fundamental ya que, abocadas al silencio impuesto por una sociedad patriarcal, van a encontrar en la carta un medio adecuado para exponer elementos pertenecientes al ámbito privado. Además, se considera que la carta es más apta para la transmisión de sentimientos - frente a la razón-, como el diario, la biografía o la confesión, por lo que también se alega este hecho para vincularlas al mundo femenino.

Conviene recordar que el interés por la carta o la epístola se manifiesta en la retórica: las artes dictaminis medievales o los formularios son una buena muestra de ello a la vez que de su carácter normativo y alto grado de sistematización (conocidas con las cinco partes en que debía dividirse toda carta: salutatio, captatio benevolentiae o expressio malevolentiae, narratio, petitio y conclusio). Si la Edad Media recibe la tradición grecolatina, ésta es sometida a un intenso proceso de formalización en el que la rica reflexión teórica presente en el pasado tanto es escritos sobre el género epistolar, en estudios generales de retórica o en las epístolas mismas, es sustituido por un conjunto de modelos que se ofrecen como objeto de imitación. Esta práctica, con el retroceso que implica en un nivel teórico literario, va a tener un amplio cultivo en los siglos siguientes, si bien es cierto que a partir del Renacimiento la epístola presenta una complejidad considerable, como se deduce de las siguientes palabras de Ynduráin (1988: 78): 
«En cualquier caso, la epístola se presta y permite las más variadas formas y contenidos. Dada la variedad de situaciones contextuales en las que puede aparecer, las encontramos dentro de otras obras, teatrales o narrativas, y pueden convertirse en novelas tanto una sola carta como una serie de ellas. Sirven para introducir otras obras, como prólogo, o identificarse con un tratado u oratio. En la realidad, coinciden con las nuevas o relaciones. Por otra parte, su naturaleza las hace especialmente aptas como vehículo de preguntas y respuestas, lo que las acerca a las questioni $\mathrm{y}$, en algunos casos, entran de lleno en esta modalidad literaria tan característica de la misma época en que florece la carta. Por la forma, la epístola coincide y eventualmente adopta los contenidos de la autobiografía y el diálogo, en cuanto esos géneros se sirven también de la primera persona.»

En principio, podemos decir que la carta interesa como manifestación comunicativa que pone en contacto al menos a dos sujetos, uno de los cuales transmite unos contenidos a los que el segundo accede y puede contestar, por lo que la comunicación, en este caso, como en toda manifestación literaria, es una comunicación a distancia que difiere de la comunicación que se establece entre varios sujetos presentes que hablan y reciben respuestas en el acto, directamente.

La existencia de cartas específicamente literarias, por otro lado, puede llevarnos a cuestionar el carácter de esas otras cartas que, al menos en apariencia, no han sido escritas con propósito estético alguno. Todo ello, sin embargo, no elimina el interés que ofrecen estas manifestaciones en el ámbito de los estudios literarios contemporáneos, sobre todo en una época en la que, tras una superproducción de estudios sobre el concepto mismo de lo literario, aún no estamos en condiciones de ofrecer una definición única, universalmente válida. Existen asimismo otros factores que deben considerarse. La carta o epístola forma parte de una amplia gama de manifestaciones escritas que se vienen englobando, por lo general, bajo el marbete de escrituras del yo o escritura subjetiva, esto es, biografías, autobiografías, memorias, diarios, etc., en torno a las cuales existe en la actualidad un interés crítico muy destacado en el que, a mi juicio, debería incluirse la carta, la cual participa, durante todo el siglo XX del cultivo abundante de una peculiar forma de escritura subjetiva cuyo carácter literario, como en los demás casos citados, habrá como mínimo que discutir, previa determinación de lo que se considera hoy que es la literatura, al igual que su concreta pertenencia a un determinado género literario. No extraña, por tanto, que Morales Ladrón (1996: 285, n. 2) afirme:

«Uno de los precedentes más inmediatos de la epístola literaria hay que buscarlo en las memorias y en el género del diario, como podrían ser los 
de Samuel Pepys (1633-1703), que nos informan de toda una serie de acontecimientos históricos. De hecho, el arte del diario creció con el de la biografía y la autobiografía, y su relación con el desarrollo de la narrativa epistolar no debe ser desestimado.»

Y es que una carta sin destinatario quedaría convertida de inmediato en un diario, una confesión o una biografía. De ahí que la existencia explícita de tal elemento de la comunicación como característica definitoria de este tipo de discurso — «la imaginación del tú por parte del yo que escribe» (Guillén, 1998:196) — no pueda ser olvidada nunca.

Es a partir de la Generación del 98 en España cuando las cartas - junto al ensayo (Concejo, 1981), al que sirve para justificar en una determinada época (Beltrán Almería, 1996: 244)—, sobre todo las de autores que han destacado en sus respectivas actividades literarias, han cobrado un gran interés por parte de la crítica. Ello se manifiesta, ante todo, en la recopilación y publicación de abundantes epistolarios. Gallego Morell (1986: 211) ha notado este hecho:

«A partir de las Cartas de Bécquer [Cartas literarias a una mujer aparecen publicadas y contienen lo que es la mejor expresión de la poética de su autor], el género se significa y se prodiga.»

El fenómeno lo explica Gallego Morell (1986: 211) en los siguientes términos:

«[...] el hecho de que la literatura española del siglo XX se comience a historiar bajo el método generacional, más o menos libremente aplicado, atrae el interés hacia el género epistolar que viene a ilustrar y a dar luz en torno a la obligada comunicación personal entre los hombres de una misma generación, aspecto que constituye uno de los ocho postulados de Petersen, plantilla obligada al ensayar una aplicación del método.»

El deseo de estudio procede igualmente de un desmedido interés por la vida privada que, aunque con antecedentes (Ariés y Duby, 1990), está cobrando tintes patológicos en los últimos años, y la prensa llamada amarilla nos ofrece abundantes muestras de ello. Este interés por lo privado se traduce en el campo de las letras en un deseo de conocer a la persona de carne y hueso cuyas obras literarias se presentan como producciones de enorme importancia que han hecho que determinados 
autores-personas pasen a formar parte de la cultura y la historia de toda una época. Si a esto unimos elementos concretos como homosexualidad, disputas, o amoríos varios, el interés se dispara.

En estos momentos, en los que la crítica biográfica no es ya lo que fuera a finales del siglo XIX y principios del XX, la vida de los escritores sigue interesando en tanto que puede ser un elemento, entre otros muchos, que contribuya a explicar su producción literaria. Las cartas, debido a la variedad señalada, pueden ofrecer valiosos elementos de interés crítico y teórico literario: el proceso de gestación de una obra, las variantes de poemas, ideas sobre el ser y la función de lo literario, esto es, poéticas, o las relaciones entre escritores y artistas de una época que sirven para reconstruir el ambiente literario de aquélla, por poner algunos casos. El reciente número monográfico de la revista Monteagudo dedicado a Epistolarios y literatura del siglo XX es una buena muestra del interés crítico-literario y el papel desempeñado por la epístola en la literatura de nuestro siglo. Es de lamentar, sin embargo, que tal proliferación de la escritura epistolar no haya ido acompañada de una consecuente teorización en nuestro siglo, época deficitaria de reflexiones en este sentido, si pensamos en la rica y extensa tradición existente al respecto.

$\mathrm{Y}$ es que aclarar el carácter literario o no literario de determinadas cartas es necesario por cuanto las cartas privadas han sido situadas, con frecuencia, al margen de la literatura, como señala Pagés-Rangel (1997: 6):

«[...] estas cartas [privadas] han sido tradicionalmente excluidas del parnaso de los géneros literarios "mayores", de la dignidad del valor estético que éstos ostentan y de la autonomía que ellos reclaman para sí. Acostumbrada a modelos de lectura que privilegian textos y géneros claramente demarcados como "creativos" o "de ficción", la crítica literaria ha preferido no adentrarse demasiado en un territorio textual que dificulta e incluso pone en cuestionamiento las premisas básicas sobre las que se instala su análisis e interpretación. Así, en el árbol de la genealogía de la literatura, la carta privada ha compartido junto con la autobiografía, la memoria y el diario un destino y un espacio temporal: como sus parientes cercanos, ha sido, hasta muy recientemente, un sub-género, una especie secundaria, un miembro de una familia hegemónico.»

La misma Roxanna Pagés señala la asociación que se establecía en los siglos XVIII y XIX entre la carta y la comunicación oral, lo que equivalía a dar una ilusión de no-ficcionalidad. La visión de la carta como una imitación del diálogo o la conversación es, como pone de manifiesto Guillén (1998: 200), uno de los tópicos que más se han 
repetido a lo largo de la tradición a pesar de que en el epílogo de $D e$ elocutione de Demetrio, o seudo-Demetrio, ubicado en el 270 a.C., se llame ya la atención sobre el hecho de que la la comunicación epistolar es una forma de escritura «y como tal no puede considerarse, a diferencia del diálogo, como la imitación de un intercambio hablado, como habla, o como simulacro de habla». Violi (1987: 87-88) entiende los epistolarios como «formas específicas dentro deuna tipología más amplia de la interacción». En términos similares se manifiesta Roca Sierra (1990: 333) tras estudiar los elementos característicos de la epístola:

«Nos encontramos, pues, ante un género sintético, fronterizo, bifronte: conjunción de dos tiempos diferentes, vínculo de dos espacios distantes, confluencia de lo puramente enunciativo con la constante referencia metatextual, límite entre la interacción dialógica y el discurso autónomo, máxima expresión, en suma, de la utilización retórica al servicio de la comunicación entre los hombres.»

0 Suárez de la Torre (1987: 177): «La carta es ante todo un instrumento de comunicación humana».

Ahora bien, decir que la epístola es un medio de comunicación es constatar una evidencia que en nada aclara su carácter de género literario, aunque facilite su estudio semiótico, ya que la mayor parte de las formas de comunicación humana no sólo es independiente sino anterior al surgimiento mismo de lo literario. (Pensemos en la conversación como fórmula primera y privilegiada.) Pero, en tanto que forma de comunicación, la epístola tiene unas características propias, como es la existencia de un emisor, un mensaje y un destinatario, constituyéndose en una forma de comunicación de carácter dialógico que entronca con la conversación, pero que, a su vez, difiere de ella porque lo que presenta es un «Diálogo diferido, un diálogo que tiene lugar en ausencia de uno de los dos interlocutores» (Violi, 1987: 89). El emisor y el interlocutor son, a su vez, narrador y narratario de un discurso que, aunque privado, puede publicarse, lo que conlleva una tarea editorial nada fácil que suele compartir buena parte de los epistolarios que son fruto de la recogida de cartas privadas que no fueron escritas para tal fin.

Si hablábamos más arriba de las dificultades que presenta definir lo literario, en el caso de los géneros literarios la situación se complica: junto a la incertidumbre de lo que pueda ser la literatura, hay que añadir el problema de determinar, en un marco amplísimo, una serie de 
delimitaciones y caracterizaciones que presentan un carácter institucional histórico y, a la vez, formal y taxonómico. Toda esta confluencia de intereses y elementos dispares está sin duda en la base de las teorizaciones que se vienen produciendo acerca del concepto de género literario en general y de determinados géneros literarios en particular durante siglos. Y en el origen Aristóteles, pues, como ha sabido resumir Garrido Gallardo (1988) en una frase afortunada, buena parte de esta teoría no es más que «una vasta paráfrasis de Aristóteles».

$\mathrm{Ni}$ que decir tiene que esta situación afecta a todas las manifestaciones literarias, pero incide más sobre aquellas que presentan, como la epístola, un carácter fronterizo ydifícilmente pueden incluirse en la categoría de «lo lírico», «lo épico» o «lo dramático» sin más. En este contexto destacan claramente dos intentos de clarificación que, sin ser excluyentes, constituyen dos importantes revulsivos que aún hoy no han surtido su debido efecto, precisamente por ello es necesario seguir hablando del tema. Me refiero a los trabajos de Guillén (1998) y Beltrán Almería (1996).

Beltrán Almería (1996: 246) apunta la, a su juicio, lamentable situación de la teoría de los géneros literarios

«Justamente porque se empeña en buscar lo esencial en lo superficial e ignora precisamente aquello que constituye el alma de la literatura, lo estético. En el terreno de los géneros literarios epistolares esto significa el intento de comprender este fenómero por el parentesco con la carta misiva, relativizando precisamente el hecho de que la misiva es un género práctico y los géneros que nos incumben ni una cosa ni otra, sino - lo que no es la carta misiva - literarios, esto es, estéticos.»

Aunque el daño que la retórica ha causado a la teoría y práctica epistolares de una determinada época es incuestionable, a estas alturas sabemos que retórica no es sinónimo de preceptiva, y que la recuperación de la disciplina clásica en su integridad, al tiempo que se enriquece, está prácticamente lograda al final del siglo XX. Por tanto, no creo que existan razones para rechazar la retórica en su globalidad, aunque la apuesta que Beltrán Almería realiza por la estética se entiende por cuanto permite al crítico establecer una relación entre la epístola y las estéticas serias y festivas tras afirmar que la carta, frente a otros géneros literarios, sólo surge con la escritura, a cuyo mundo pertenece. 
Entre reflexiones oportunas, Beltrán Almería habla de «géneros epistolares», pero ¿existen los géneros epistolares?, y, si existen, ¿cuáles son? Considerar como géneros epistolares aquellos que la tradición, desde el mundo griego, nos viene presentando como tales en un momento u otro de este vasto período de tiempo no facilita una mayor comprensión teórica, ya que, primero tendríamos que recordar que la literatura no ha existido siempre, y, segundo, si cuestionamos la teoría y las categorías genéricas heredadadas, no podemos, al mismo tiempo, aceptarlas en un caso concreto sin la consecuente justificación teórica. Un repaso a la distintas teorías de y sobre los géneros literarios que han aparecido en el siglo XX (Garrido Gallardo, ed.,1988) nos puede mostrar la existencia de un gran interés y no pocos esfuerzos, si bien es cierto que el formalismo imperante en buena parte de este período es el que ha determinado el mayor número de estas teorías empeñadas con frecuencia en cambiar nombres y establecer más clasificaciones atendiendo a criterios formalista-estructurales, lingüísticos en definitiva - ya se trate de lingüística tradicional o lingüística del texto-, que no parecen haber zanjado el problema, ya que todas esas teorías se ven desbordadas por una práctica discursiva variada, rica y compleja. Este hecho no conlleva ninguna descalificación puesto que lo normal es que los avances en el campo de las Humanidades se produzcan de forma paulatina; en este sentido hay que apreciar en su justa medida los esfuerzos de Todorov, Genette, Van Dijk, Bajtín y otros muchos por establecer en los géneros literarios nuevos criterios o modificar los ya existentes. Y también los esfuerzos de Beltrán Almería cuando llama la atención sobre la situación de los «géneros» epistolares.

A Claudio Guillén le debemos una lúcida reflexión sobre literatura y epistolaridad. No basta, como señala el teórico, con que las cartas estén bien escritas para poder hablar de literatura. Por ello recurre a tres criterios básicos: la capacidad de leer y escribir, la literariedad y la poeticidad, términos estos últimos tomados de la Teoría de la literatura de García Berrio y entendidos en un sentido concreto:

«La literariedad es, según él [García Berrio], una opción con la que el escritor y el lector se comprometen desde un principio. La poeticidad es un valor producido por la escritura y la lectura, por medio de la intervención de una imaginación simbólico-imaginativa que no es meramente individual, sino ampliamente representativa o, puede decirse, antropográfica» (Guillén, 1998: 179).

A pesar de que los citados criterios son cuestionables, y más si tenemos en cuenta la crítica del profesor Guillén a aquellas escuelas crítico- 
literarias empeñadas en centrarse en el lenguaje de los textos, en sus procedimientos verbales, este hecho no le impide señalar elementos de importancia teórica incuestionable en relación con la epístola. Así que, aunque la ficción o la ficcionalidad es importante en la determinación de lo literario, ni toda manifestación literaria ha de ser necesariamente ficticia ni, sobre todo, toda manifestación ficticia es literaria, por lo que aplicar este criterio al campo epistolar nos conduciría a

«dar cabida a cartas que no son literatura, o lo son ambiguamente, o se encuentran al borde de las instituciones literarias; y que por lo tanto superan, gracias a la vasta dimensión de lo ficcional, la severa dicotomía que divide las cartas en dos áreas o campos absolutamente heterogéneos» (Guillén, 1998: 180).

Se refiere a los géneros epistolares frente a las cartas llamadas reales. De ahí que se imponga resaltar que, aunque sea ficcional, la carta no es novela, ni autobiografía, ni diario íntimo, pues en ella destaca la orientación hacia un destinatario. Por otra parte,

«La carta, y ello es decisivo, procura no suprimir el requisito inicial de veridicidad. De tal suerte se va produciendo y estableciendo la ilusión de no ficcionalidad epistolar, que, a diferencia de otras, supone de manera específica la copresencia en un mismo entorno - más o menos amplio por supuesto del receptor de la carta» (Guillén, 1998: 187).

De ahí que proceda hablar de un doble pacto epistolar: el que conlleva la aceptación por parte del lector real de la necesaria vinculación del «yo textual» de la carta al «yo real» y un segundo pacto relativo al hecho de que el lector también existe desde la perspectiva de quien escribe la carta y está vinculado además al «tú textual».

Hasta aquí el profesor Guillén caracteriza oportunamente esta concreta manifestación discursiva, pero intentar situar tales teorías en determinados moldes genéricos conlleva no pocos riesgos. En principio, al borrar la distinción entre carta imaginada y carta real, la determinación del posible carácter literario de éstas se complica -y la amplitud y variedad de fenómenos que encontramos aquí pueden detectarse en otros ámbitos discursivos en los que también nos interesa determinar su carácter literario o no literario-, ya que, en términos generales, aunque una carta imaginada puede ser real, esto es, el autor puede contar hechos imaginados al receptor, una carta imaginada es 
fundamentalmente literaria, aunque también puede incluir algún que otro elemento real. En segundo lugar, fundir carta familiar, epístola en verso y novela epistolar en tanto que «los tres géneros principales que el cauce de la comunicación epistolar hizo posibles» (Guillén 1998: 208-209) conlleva una simplificación de manifestaciones muy diferentes entre sí -y, por otra parte, escasas en el marco de los múltiples discursos de carácter epistolar - que contradice la complejidad y variedad del fenómeno epistolar que Guillén señala en más de una ocasión.

El problema en la teoría de este autor surge no sólo por la utilización de conceptos de operatividad cuestionable como literariedad y poeticidad, sino por un intento de clasificación genérica que le conduce, obviando sus propias teorías en este ámbito (Guillén, 1985), y sin obtener con ello resultados positivos, a recurrir al concepto de «género autorial» que expone Cabo (1992) en relación con la literatura picaresca como género que se va conformando en el texto al tiempo que se utiliza, o a las teorías que Genette expone en Ficción y dicción (1991) sobre poética constitutiva o condicional —obra en la que se nos presenta, dicho sea de paso, una clasificación de los géneros literarios basada en la dicotomía ficción/poesía más que cuestionable, ya que pocos o ninguno son los argumentos que pueden esgrimiese en la actualidad contra el carácter ficticio de la poesía-.

Puestos a buscar un espacio a la epístola en el marco de los géneros literarios tal como está fijado en la teoría del siglo XX, también podríamos recurrir a la misma distinción que Guillén (1985) establece entre cauces de representación, géneros propiamente dichos, modalidades y formas; o la distinción de Bajtín (1929) entre géneros monológicos y dialógicos ampliando estos últimos más allá de la novela; o la nada desdeñable consideración de Genette (1977) entre serie genérica, grupo genérico, antigénero, contragénero o plurigénero. Pero todos estos intentos de inclusión serían forzados como ocurre con otras muchas formas de escritura actuales que se vienen considerando literarias y que en la práctica van delante de la teoría, porque no podemos negar que la mezcla de las tres categorías clásicas —esto es, la lírica, la épica y la dramática - es bastante frecuente en nuestro siglo. Dar prioridad a los conceptos heredados antes que a la realidad literaria de una época constituye un error que ya denunciaron quienes se opusieron frontalmente a la preceptiva. Y es que si la teoría de la tragedia de Aristóteles presenta una solidez tal que la ha hecho pervivir a lo largo de los siglos es porque Aristóteles teorizó sobre la realidad literaria de su época, y así lo puso de manifiesto sin complejo alguno. 
A estas alturas, sin embargo, la dilucidación de las distintas cuestiones de índole crítica y teórico-literaria presenta mayores problemas por la existencia de una serie de vicios heredados que en muchas ocasiones se consideran verdades incuestionables e imperecederas. Por ello urge un cuestionamiento radical en este ámbito, requisito indispensable para poder alcanzar un avance real y dejar de dar vueltas en torno a un mismo eje desgastado. Como ha sabido señalar certeramente Schaeffer (1983: 157):

\begin{abstract}
«Hay que ver claramente que lo que se ventila en este debate no es ya literario ni incluso epistemológico, sino ontológico, puesto que atañe a la teoría del ser: quid/quod est? Los sistemas genéricos románticos (el de Fr. Schlegel, por ejemplo), los del idealismo alemán (Schelling, Solger y Hegel), al igual que la teoría de Croce, tienen, a este respecto, una ventaja segura sobre los innumerables sistemas o anti-sistemas posteriores que se inspiran en ellos: que formulan explícitamente la apuesta ontológica que constituye el fundamento real de su discurso genérico. Hay que añadir inmediatamente que, al fin y al cabo, sin embargo, esa ventaja es inútil, porque lo único que hace es imponer la conclusión de que toda argumentación racional es imposible en este campo teórico en el que decidirse por una u otra teoría genérica implica que uno pasa con todos sus trastos al campo de la ontología correspondiente.»
\end{abstract}

Para terminar, y habiendo hecho una síntesis significativa en torno a la teoría contemporánea de la epístola, se puede afirmar que las contribuciones, en lo que se refiere a su caracterización, son importantes y sin duda constituyen una base que deberán tener en cuenta los investigadores en el futuro. Sin embargo, en lo relativo a la determinación del concreto carácter literario que pueda presentar la epístola moderna teniendo presentes todas sus posibles variantes así como el género en el que deberían incluirse, la situación es sumamente confusa, pues las afirmaciones basadas en la inercia de la tradición — «géneros epistolares», «la epístola como género»- son a todas luces insuficientes. La revisión de la cuestión genérica propuesta más arriba es del todo necesaria en este campo, y, si tal revisión tarda en llegar, ello no debe constituir un obstáculo para que la reflexión sobre el tema continúe, ya que no se trata de una cuestión aislada por cuanto en este tránsito de milenio nos encontramos con numerosas manifestaciones discursivas que están en espera de que una disciplina de sólidos fundamentos teóricos determine su carácter literario así como el lugar que han de ocupar en este campo. $Y$ no son pocas las manifestaciones discursivas que, al igual que la epístola, se mueven fundamentalmente en la esfera del sujeto ( $y$ en la de lo subjetivo, aunque no entendido como lírico), 
hecho que hay que ligar al papel desempeñado por el sujeto no sólo tras el surgimiento y consolidación de la burguesía, sino también, y sobre todo, en el pensamiento postmoderno que tanto ha pregonado su crisis y desmantelamiento definitivo. Pero, como todos sabemos, el sujeto no ha muerto, y para demostrarlo tenemos una abundante escritura que no puede ser leída ni teorizada al margen de esta categoría en la que sin duda habrá que situar la base de futuras teorizaciones, las cuales, por otra parte, no podrán ignorar tampoco que este concepto, desde el siglo XVIII hasta la actualidad, ha cambiado. Por ello, no parece arriesgado afirmar que la epístola, junto a otras muchas manifestaciones literarias importantes desde el siglo XVIII y abundantes en nuestra época, debe incluirse en un género de escritura - se llame como se llame - en la que se destaque, se teorice oportunamente y se determine la presencia y función del sujeto.

\section{Referencias bibliográficas}

ArIÉs, Ph., y Duby, G. (eds.) (1990). Historia de la vida privada. Sociedad burguesa: aspectos concretos de la vida privada. Madrid: Taurus, tomo 8.

Batin, M. (1929). Problemas de la poética de Dostoievski. México: FCE, 1986.

Beltrán Almería, L. (1996). «Las estéticas de los géneros epistolares». $1616 \mathrm{X}, 239-246$.

CABo Aseguinolaza, F. (1992). El concepto de género y la literatura picaresca. Santiago de Compostela: Universidad de Santiago de Compostela.

CONCEJO, P. (1981). «El origen del ensayo hispánico y el género epistolar». Cuadernos Hispanoamericanos, 158-64.

Gallego Morell, A. (1986). «Las cartas de Lorca y Lorca en sus cartas». En Soria Olmedo, A. (ed.), Lecciones sobre Federico García Lorca, 197209. Granada: Edición del Cincuentenario.

Garrido Gallardo, M. Á. (ed.) (1988). Teoría de los géneros literarios. Madrid: Arco/Libros.

GeNETTE, G. (1977). «Géneros, "tipos", “modos". En Garrido Gallardo, M. Á. (ed.) (1998), 183-233.

- (1991). Ficción y dicción. Barcelona: Lumen, 1993.

GuIllén, C. (1985). «Los géneros: genología». En Entre lo uno y lo diverso. Introducción a la Líteratura Comparada, 141-180. Barcelona: Crítica.

- (1998). «La escritura feliz: literatura y epistolaridad». En Mútiples moradas. Ensayo de Literatura Comparada, 177-233. Barcelona: Tusquets. 
López Estrada, F. (1960). Antología de epístolas. Cartas selectas de los más famosos autores de la historia universal. Barcelona: Labor.

Morales León, M. (1996). «La dialéctica entre la presencia y la ausencia ficional del destinatario en el discurso epistolar". 1616 X, 285-295.

PAGÉs-RANGel, R. (1997). Del dominio público: Itinerario de la carta privada. Ámsterdam: Rodopi.

RICO VERDÚ, J. (1981). «La epistolografía y el "Arte nuevo de hacer comedias"». Anuario de Letras 19, 133-162.

RoCA SIERRA, M. (1990). «Retórica del discurso epistolar». En Investigaciones Semióticas III. Retórica y lenguajes, II, 327-34. Madrid: UNED.

SCRAEFFER, J-M. (1983). «Del texto al género. Notas sobre la problemática genérica». En Garrido Gallardo, M. Á. (ed.) (1998).

SUÁREZ DE LA TORRE, E. (1987). «Ars epistolica. La preceptiva epistolográfica y sus relaciones con la retórica». En Morocho Gayo, G. (coord.). Estudios de Drama y Retórica en Grecia y Roma, 177-204. León: Universidad de León.

VIOLI, P. (1987). «La intimidad de la ausencia: formas de la estructura epistolar». Revista de Occidente 68, 87-99.

VV.AA. (1998). «Epistolarios y literatura del siglo XX». Monteagudo 3 [monográfico].

YNDURÁIN, D. (1988). «Cartas en prosa». Academia Literaria Renacentista V-VIII, 53-79. 